\title{
Moving to Block Teaching during the COVID-19 Pandemic
}

\section{Chrissi Nerantzi,}

\author{
Gerasimos Chatzidamianos
}

\section{Manchester Metropolitan University, United Kingdom}

\begin{abstract}
This paper is an exploration into the block teaching format in the context of Higher Education during the COVID-19 pandemic. It provides practical guidance to course designers that will aid their planning, organisation and offering of learning and teaching using block teaching in online and blended settings. The paper attempts to resolve some of the learning and teaching dilemmas and increase focus and flexibility of provision, while avoiding disruption and interruption of study during the pandemic. While the paper refers to a particular block teaching format that has been implemented in a UK post-1992 institution across its undergraduate and postgraduate courses, this exemplar of block teaching will also be useful for other institutions and course designers who are considering the block teaching format in Higher Education settings at module, programme, departmental or institutional level.
\end{abstract}

Keywords: Block Teaching; Blended Learning; Online Learning; Active Learning; Pandemic; Higher Education 


\section{Introduction}

In the context of digitalisation of Higher Education (HE) as a response to the COVID19 pandemic, universities made changes to the way their programmes and modules are offered. Block teaching is one of the formats commonly used for curriculum delivery at the institutional level. Traditionally, university students, especially on full-time programmes, study more than one module and often work on more than one assessment simultaneously. That means that their attention and learning effort are split across different topics often on a daily and hourly basis, therefore there may be a disconnect between learning activities and assessments as well as conflicting priorities and demands. Block teaching on the other side, means studying one module (or maximum two) at a time during a condensed or compressed time. Such examples are reported by Kofinas et al. (2017) in a postgraduate business programme, by Dixon and O'Gorman (2020) who explored tutors' perceptions of block teaching in an undergraduate programme in Tourism Management programme by Swain (2016) who explored the first year campus-based block teaching experience in an undergraduate business course. The authors came to similar conclusions regarding the increased focus block teaching created for students. There are some studies around block teaching that suggest that it is used in HE and secondary education primarily as a campus- or blended- mode of delivery. However, there is still relatively limited research in this area and more evidence of the effectiveness of block teaching would be beneficial for institutions and the sector (Davies, 2006; Dixon and O'Gorman, 2020).

Rettig and Canady (2013), in their book about block teaching in secondary schools in the US, outline the opportunities this format brings to teachers and students. They suggest that block teaching creates greater flexibility for self-paced learning and can foster more student participation while also allowing for greater creative interventions and collaborative learning as students do not jump, from one subject to another daily. This arrangement can create a more connected and immersive but also a more intense learning experience for the students, one that is also deeper and more focused. This, however, needs to somehow be counterbalanced with the view that learning is more efficient if students are given breaks between learning sessions (Fenesi et al., 2018). It seems that block teaching creates more focused opportunities for active participation and collaborative learning as the same students will be together for longer periods. This, therefore, enhances the opportunities for shared experiences and belongingness and builds a sense of community much quicker than there would be in an on campusbased, face-to-face delivered traditional programme of study. In fact, there is some evidence suggesting that students generally find block teaching less stressful, and rarely want to go back to traditional teaching format (Swain, 2016).

According to Swain (2016), there are two factors that define success in block teaching: planning and timetabling, with the latter being significantly more complex than in face-to-face delivery. However, in a block teaching pilot in Logistics in HE, Grant (2001) found that students' interaction, engagement and academic performance increased and relationships between students and tutors became stronger. Similar results were recorded by Swain (2016) in a first-year undergraduate course that also showed that there was a higher degree of student enjoyment and that students felt that

International Journal of Management and Applied Research, 2020, Vol. 7, No. 4 
they had a voice, they felt being listened to and heard and also received feedback more promptly. However, while Dixon and O'Gorman (2020) acknowledge that block teaching improved tutors' time management, the intensity of block teaching generated challenges for tutors who started spending more time supporting students. Also, while students might engage with one block at a time, staff are likely to be involved in multiple blocks simultaneously, which have a priori impact on staff workload. Importantly, the close and intense working relationship over a specific timeframe can cause fatigue among staff and students (Swain, 2016). Dixon and O'Gorman (2020) further acknowledged that although fewer topics and concepts could be explored during a block, those explored reach a deeper depth. However, the authors founds that block teaching was progressively seen less favourably and led to the disengagement of students especially when they missed face-to-face block days as well as challenges for students to complete the assessment, when this followed the block; both significant points that HE staff should be mindful of when designing their blocks.

These observations illuminate that a rethink linked to the way a block is structured and how it is assessed is required. Robbins et al. (2000: 2) state that "teachers must have multiple opportunities to develop active teaching strategies in their various disciplines. Lecturing for large amounts of time becomes a major problem with a block schedule." Similarly, Hackmann and Schmitt (1997: 1-2) argued that “... some teachers may naively assume that they can force-fit two "old" lessons into this restructured time frame. Teachers soon learn, however, that they cannot take the simplistic approach of using the same methods they did before". Regardless, while there may be some resistance to change and adopt block teaching, there is evidence that suggests that tutors who have tried it would not revert to the previous curriculum format (Kofinas et al., 2017), a fact also echoed by students too (Swain, 2016).

It is within this context that this paper aims to provide answers to a key set of questions that course designers, programme and module teams in HE need to consider when redesigning their curriculum. It is envisaged that the move to blended block teaching is offered with the view to increase flexibility and responsiveness to students' needs during the pandemic so that modules and programmes can continue whilst accounted for the restrictions placed. It is noted that some of these changes might be beneficial or continue to be implemented after the end of the pandemic. While what follows relates to the introduction of a specific institution-wide implementation of block teaching in a particular format (see below), the following questions will also be relevant to other institutions and programmes which are considering a different block teaching format for their course provision.

\section{When to offer a block module}

Frameworks for block teaching vary in shape, length and mode of delivery, and some often include intensive face-to-face days. Block, or intensive mode of teaching, can stretch from weekend to evening mode, to a few days to a week, or two weeks to multiple weeks but still much shorter than a normal term or semester and is often linked to a specific module or programme (Davies, 2006; Dixon and O'Gorman, 2020; Kofinas et al., 2017).

International Journal of Management and Applied Research, 2020, Vol. 7, No. 4 
A framework the authors of this paper are particularly familiar with is one that has been adopted by a university in the UK at an institutional level across all programmes in all disciplines and professional areas during the COVID-19 pandemic. This consists of six weeks blocks, four blocks spread over the academic year that are offered fully online or in blended mode. The rationale is that each block will consist of one 30 or two 15 credits module with an additional week for assessment (i.e. $6+1$ weeks). A 30 credit module could also be delivered across two consecutive blocks. Furthermore, large cohorts could be divided into two and a module could be delivered across two blocks. An indicative example from a Department of Psychology regarding the breakdown of contact hours per week is below:

- 1 hour for a synchronous session per approximately 20-25 students per week (remotely)

- 1 hour of support session of the entire module cohort per week (remotely)

- 1 hour of optional curriculum enrichment activities per week (face-to-face, when allowed and remotely otherwise)

- 30 minutes of group personal tutor meeting per week (approx. 15 students) (remotely)

- 15 minutes of individual personal tutor meeting per block (remotely)

- 5 hours-worth of asynchronous learning activities and materials that are studied by the student independently

The synchronous session is dedicated to the provision of formative feedback on the material studied the previous week (i.e. consolidation of independent learning), real time group activities (i.e. workshop style) and preparation of the material and learning activities for the following week.

Regardless, as the first step, programme leaders and course designers need to apply a degree of realism whilst deciding the order of core and optional modules of a programme as a whole. This also includes conversations with the team and academic managers about resourcing. Team teaching can potentially help with sharing the load, reducing feelings of intensiveness of teaching in blocks, but also account for technical difficulties that might arise during synchronous sessions (see later). Larger modules will, in effect, present additional administrative and procedural challenges in this respect (consider delivering them across two blocks).

A programme team will need to work collaboratively and decide which modules need to be offered in which block so that learning follows a progressive pattern. Hence, when deciding which modules should be offered first in each year or level, the focus should be how we can progressively help students develop particular competencies, create stimulating learning opportunities that help them connect with the subject but also with their peers and their tutors at a personal level and at all times considering what is realistically possible and how. For instance, theoretical modules might need to be offered before more practical ones. This may mean that the entire academic year is turned back to front. Regardless, the lessons learned from what has worked on campus and face-to-face is most likely not going to be as useful to guide these decisions. Resourcefulness, creativity and novel ideas will be needed to help academics to reevaluate what they knew, re-think and explore what could work online and in a

International Journal of Management and Applied Research, 2020, Vol. 7, No. 4 
blended format at the same time if possible, what could be adapted and how and what they need to let go.

\section{What to teach in a block module}

Block teaching is a time-intensive and condensed pedagogical approach, shorter than a term or semester. In this particular implementation of block teaching across a whole institution, academics will be attempting to work out how to "deliver content" within 6 weeks instead of 10 or 12 weeks and what "content" will fit. While the planning and organisation used in block teaching will differ from a traditional term or semester long module, one key aspect of each module remains the same: the learning outcomes.

The learning outcomes of a module provide a useful starting point and operationally, these should form the pillars upon which the block module will be built. What do I want my students to learn? What do they actually need from this module? What are the fundamentals? What challenges will the students experience? What will be most troublesome for them? What will enable the students to meet the learning outcomes, perform well in the assessment and want to learn more to pursue their own interests linked to the subject? Questions like those will help to make the decisions and constructively align the learning activities to the learning outcomes and the assessment. For the alignment of the assessment, in particular, academics need to consider whether the existing assessment over- or double-assesses the learning outcomes. Is there a need to streamline? Can the assessment be simplified? Can the assessment be operationalised progressively? Programme designers and module leaders should consider developing creative ways by which the assessment is embedded in the weekly activities in ways that students receive formative feedback without the need for additional hours dedicated specifically to assessment preparation.

When it comes to what is taught, it is important to consider that students may have a particular interest in specific aspects of the module, which they may be keen to pursue and explore further and this needs to be enabled. In effect, learning activities could operate as the means that provides a framework within which students embark on an exploration of a particular topic of their own choice.

However, learning outcomes might not provide enough ground to help us what to focus on. A lot of learning, however, can happen without teaching (Illich, 1971). In block teaching, going back to the essentials, the fundamental concepts will help us organise and plan. These concepts are fundamental to our professional area/discipline; what Meyer and Land (2006) refer as threshold concepts which are transformative, troublesome, irreversible, integrative, bounded, and discursive and therefore lead to a shift in thinking. Mastering them is what leads one to become what they study. But in order to grasp them they need openness and flexibility of mind, deep discussion and critical debate to untangle the messiness of new knowledge and fully understand them.

Threshold concepts are of importance for every discipline and professional area and fundamental in becoming a professional. While students can learn a lot on their own, the threshold concepts of a discipline or professional area are usually the ones that

International Journal of Management and Applied Research, 2020, Vol. 7, No. 4 
need a support scaffold to be digested and understood by students so that they can move forward in their learning (Meyer and Land, 2006). Once identified, the threshold concepts can be turned into the stepping stones, chunks or building blocks that learning will occur within a block module. The chosen concepts will help structure the modules. Building-in interaction and activities will bring the concepts to life.

A structure using threshold concepts could be simple. The approach should resemble the process whereby one strips the layers of the onion and focuses on what truly matters, by having a less-is-more attitude (Chatzidamianos and Nerantzi, 2020). This does not mean that students will learn less. Learning a priori happens anywhere and students can be encouraged to take full ownership and responsibility for their learning beyond the boundaries of the block module. Students could be encouraged to reach out and join professional networks and communities where they will be able to find a plethora of open courses or materials they could sign up to or use to complement their learning. This way, the development of independent thinking and learning that transfers beyond the module and programme boundaries will be supported. The indicative hours of directed and independent learning required per module depending on its structure and the number of credits it carries provide a useful guide of learning expectations that are organised and self-organised. Through a simple structure students will be able to navigate easier through the block module and filter out more and less important information.

\section{How to teach a block module}

Lectures are not useful to guide module design decisions for remote or blended delivery in a block teaching format. A 50-minute traditional lecture for example may not work online if it is entirely based on presenting information and it will be too long and ineffective as it is not based on interaction, questioning and active participation Also, the remote environment, especially when cameras are deactivated, limits the opportunities for the academic to gage the student's understanding and respond to what is often communicated non-verbally. Mazur (1997) identified problematic issues with this approach in face-to-face settings more than 20 years ago and developed the peer instruction approach to engage students more actively in the learning processes. Information sharing sessions could be turned into a short recording that students could watch in their own time with an accompanying activity to make learning active. Also, a three-hour on-campus seminar does not translate into a three-hour live online session. Can it become a set of activities, to be discussed over a day or longer? Hence, any pre or post synchronous session learning activities and reading should be timed so that students know exactly what is expected of them. It is equally important to rethink studio, labs, and small group interactive activities. With the encouragement and guidance of the academic, students will want to uncover and discover. It should not be about "covering content". Students' context is important, their reality too. It is useful to think about how their world can be brought into the module so that what they bring can be maximised and, as mentioned previously, help them pursue their own interests too.

Learning online can be lonely, although it does not and should not necessarily be that way. Whilst considering the students' reality, thinking about students as people and

International Journal of Management and Applied Research, 2020, Vol. 7, No. 4 
how to connect with them, how to support their learning will be helpful. Learning technologies most academics have access to can one way or another help foster a sense of belongingness. However, for an effective and meaningful interaction through any online platform, building and fostering collaborative relationships is the key for that interaction and engagement to happen. Partly, this requires academics to show that, whilst they are experts on their field they are also approachable and authentic human beings, who empathise, who care, are present and part of the learning process.

Following Biggs' (1996) constructive alignment (Figure 1), it is beneficial to design activities that work remotely and possibly on campus too. Using constructive alignment helps remaining focused and helps developing creative ideas of studio and lab work that can work equally well online and on campus. Building in variety and creating learning experiences that will help students gain progressively a deeper understanding of the discipline or professional area are equally important.

Figure 1: based on Constructive alignment

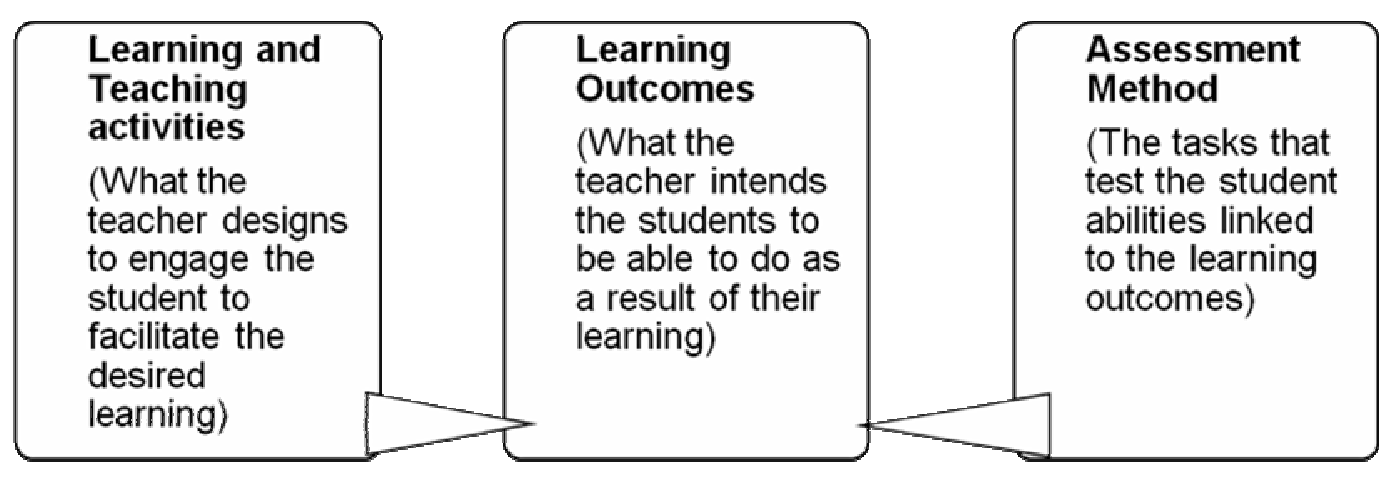

Source: Biggs (1996)

Online learning does not mean learning exclusively online. A lot of learning can happen offline away from digital and networked devices, alone and with others. Furthermore, when learning online, coming together with others should not exclusively or primarily mean through live sessions or synchronous sessions. Deeper learning happens when done asynchronously (Ke and Xie, 2009; Nerantzi, 2017). Asynchronous learning and teaching activities add flexibility as this mode of learning is self-paced and not located specific and is therefore seen as more convenient (Gilpin, 2020). They can engage students anytime, from anywhere, anyhow. Therefore, beyond any synchronous or live sessions, active learning strategies such as discussions, debates, projects, problems, case studies, scenarios and making activities, should be considered to name just a few. The use of flipped learning (Bergmann and Sams, 2012) or peer instruction (Mazur, 1997) can work well in the blended and fully online classroom and create opportunities for seamless learning (Nerantzi, 2020). However, setting up the activities and then stepping back is not the best approach. Academics need to be present, participate, model engagement, interaction, comment and give feedback. In other words, be there with them. To make this happen, however, it is imperative that programme managers factor such requirements in the planning of the staff workload.

International Journal of Management and Applied Research, 2020, Vol. 7, No. 4 
While there are many benefits of asynchronous teaching, there is also the need to connect with students synchronously. Video conferencing platforms have been extensively used recently since the start of the pandemic, but have they always worked? Was it the right decision to use this over a different approach? Often a blend of synchronous and asynchronous interactions is suggested as a more effective way forward (Gilpin, 2020). It is certainly the case that students and academics alike value seeing each other. It is important for academics to connect with their students so they can build professional relationships, a learning community, trust and a safe space. In those cases, using live sessions for this purpose will speed up the process and help academics enable social interactions and lay the foundations of a learning community to form (Gilpin, 2020). However, there are also issues. The "digital inequality stack" is the complex and interrelated nature of digital inequalities (Robinson et al., 2020), has become more apparent due to the pandemic. Some students may not have internet access or equipment (Office for National Statistics, 2019). Furthermore, Sklar (2020) highlighted the issue of "zoom fatigue" due to overuse of video conferencing could cause cognitive overload.

However, when connecting live through video conferencing platforms, the process allows access to peoples' personal lives that would not otherwise be the case in an amphitheatre or a classroom. Being mindful, in effect, of the additional possibly more personal information that is been shared is key. This is of particular importance as a) it could expose some truths that people might not want to share with implications on safeguarding vulnerable individuals and b) there could be issues related to data protection from the use of the platforms themselves that need attention. A good strategy is to check with students first and only share a live video if all present are comfortable and agree with its use. Programmes should be developed with an online communication etiquette that is shared with the students at the beginning of the block, so that expectations are clear. Further, in synchronous sessions it needs to be ensured that sessions are inclusive and meet people's needs. For a deaf student, for example, hosting a synchronous session exclusively with audio or one with videos without captions embedded will not be appropriate. Subtitles or the presence of a sign language interpreter would also be needed, both of which requires solid planning and a lot additional preparatory work. The key point is that while the aim is to be inclusive, inadvertently the design may create barriers for learning and is exclusive. Some students may not have the technology or connection speed needed or are not available at the specific time the synchronous sessions are offered. The majority of what is designed for a module should, therefore, be asynchronous so that they can be accessed anytime, from anywhere, anyhow and in effect, engagement will provide more flexibility.

In designing each block module it is advisable to consider it as a collection of learning chunks that are based on the threshold concepts. These can define how many chunks are allocated in the module and each week. It could be that a particular chunk needs to be stretched over a week or more - it all depends on the concept itself and the discipline or the professional area. A metaphor that could help with visualising the design of a chunk is that of sewing patterns. Imagine designing t-shirt when designing

International Journal of Management and Applied Research, 2020, Vol. 7, No. 4 
a learning and teaching chunk. To produce t-shirts, a t-shirt pattern is needed that consists of various sections, such as the front, the back, the sleeves, etc. The pattern is designed once and can then be re-used to make multiple t-shirts. Although the pattern might be identical, the fabric, for instance, might be different. This results in variation, which is really important in learning and teaching. Applying this metaphor in a block module and particularly when organising and planning the learning and teaching chunks within blocks, the curriculum pattern needs to be developed first and used as a tool to design the concept-driven chunks for each block module. The pattern needs to be designed in line with what is aimed to be delivered in each module. To follow up with the metaphor, consider Figure 2, whereby different sections of the t-shirt pattern correspond to different parts of the module: learning outcomes, activities, input, assessment, and meet-ups.

Figure 2: T-shirt pattern to design the curriculum

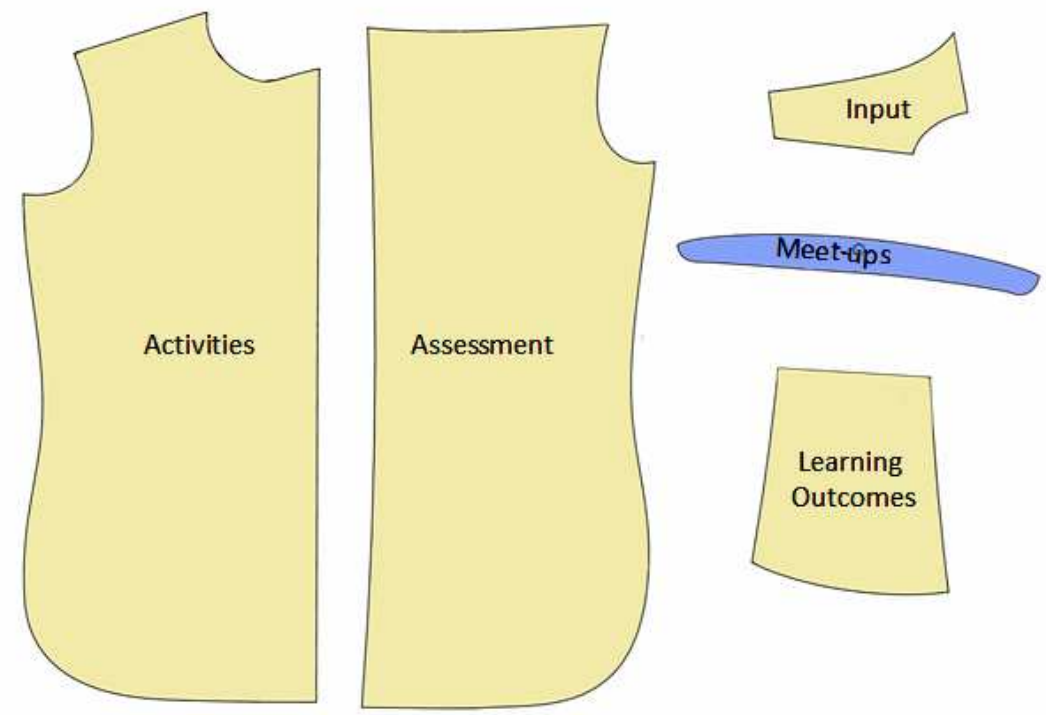

Note: Sections in yellow indicate potential asynchronous or flexible delivery and the section in blue points to synchronous mode

Assuming that the block module has four chunks, the pattern would then need to be repeated 4 times, creating, in effect, the basic block module structure which can be built-in into any Virtual Learning Environment used locally. To allow for variation between chunks, it is sufficient to only change one section of the pattern. The overall structure, however, needs to be visualised from the outset so that the path through the module is clear and cohesive with progressively increasing complexity and can be navigated easily. Nerantzi (2017) reviewed and summarised a series of empirical and conceptual design frameworks and models that have been developed to support learning with technologies (see Table 1). In her review, Nerantzi (2017) identified that these frameworks had four common characteristics that foster learning supported by digital technologies in a range of settings and can provide a useful evidence-based guide in how to construct a block module and identify priorities. The four characteristics are activities, tutor support, choice and community. Readers interested in exploring these frameworks further may find the Community of Inquiry Framework

International Journal of Management and Applied Research, 2020, Vol. 7, No. 4 
(Garrison et al., 1999), the 5-stage model (Salmon, 2002) and the 3E Framework (Smyth, 2009) useful.

Table 1: List of reviewed design frameworks

\begin{tabular}{|c|c|c|c|}
\hline $\begin{array}{l}\text { Year Framework } \\
\text { first } \\
\text { appeared }\end{array}$ & $\begin{array}{l}\text { Type of } \\
\text { framework }\end{array}$ & $\begin{array}{l}\text { Formal/ } \\
\text { informal }\end{array}$ & $\begin{array}{l}\text { Designed for mode } \\
\text { of application }\end{array}$ \\
\hline
\end{tabular}

1971 Supported Open Learning model (Swann, 2004; Jones et al., 2009)

Conceptual Formal Distance learning

1991

Community of Practice (Lave and

Wenger, 1991)

Empirical Informal Learning

2000 Community of Inquiry framework

(Garrison et al., 2000; 2010)

Conceptual Formal Blended learning

$2002 \quad \begin{array}{ll}\text { 5-stage model } \\ \text { (Salmon, 2002; Salmon, 2013) }\end{array}$

Empirical Formal Online learning

2009 3E Framework (Smyth, 2009)

Empirical Formal Blended learning

7Cs of the Learning Design
Framework (Conole, 2013)

Conceptual Formal Blended learning,

5C Framework (Nerantzi \&

Beckingham, 2015)

Conceptual

Formal, informal

Online learning

2017

Online Collaborative Learning Theory (Harasim, 2017)

Empirica

Formal

Online learning

Reproduced from Nerantzi (2017: 72)

Using a framework will aid the construction of a block module scaffold and a learning and teaching design. It can also help to resist the temptation to use many and possibly new or untested or complex digital technologies. It is often best to start with those technologies that one is familiar with and importantly the ones that are supported by the institution. Extra digital technologies, such as social media platforms and mobile apps as well as open educational practices that can further support and extend learning opportunities beyond institutionally supported platforms can also be considered (Buckley et al., 2017). It is best, however, to start with simple and manageable options, and progressively introduce additional digital tools and platforms if and when they would add something to the learning process. Importantly, although some of the students might have been holding a tablet from when they were a toddler it does not necessarily mean that they know how to use digital devices for learning. Hence, a good starting point is to experiment with them but start with what is familiar to build and boost confidence.

International Journal of Management and Applied Research, 2020, Vol. 7, No. 4 
As a rule, the point at which one feels overwhelmed by the volume of the new resources that they need to develop should be perceived as an indication that their pattern design is overly complicated and needs rethinking. A simple pattern for chunking learning and teaching in a block module is desirable.

\section{Conclusion}

Block teaching has the potential to foster greater engagement, bring flexibility to academic programmes and modules and if it is developed, structured and implemented based on an informed evidence-based pedagogical rationale it can help students meet their needs (Davies, 2006) and achieve better learning results and enjoy learning more (Dixon and O'Gorman, 2020). Particularly, during the time of the COVID-19 pandemic, block teaching can provide a useful formula to manage social distancing on campus and contact tracing, bring focus and flexibility to the curriculum and make the transition between fully online and blended mode smoother when needed without extensive re-organisation (Glazer, 2020). Furthermore, block teaching enables tutors to dedicate their undivided attention on teaching one module at the time (Redden, 2020) and by doing so it ensures more focused learning experiences and support within a shorter period of time for students. However, staff development will be crucial in preparation for block teaching implementations and integrating mechanisms to evaluate this format will provide useful insights for future changes to make block teaching effective in particular settings.

In this article learning and teaching in blocks in Higher Education was explored from a design perspective to aid course developers and designers preparing and organising for the coming academic year. The suggestions are routed on evidence-based approaches that maximise inclusive learning opportunities, provide focus and flexibility. While the motivation of this paper is linked to an institution-wide implementation of block teaching at a university due to the COVID-19 pandemic to reduce complexity of an academic programme and potential making learning online or in blended mode more manageable during the pandemic enabling students to focus on one module at the time, the ideas shared may also be useful when considering block teaching in other settings within a specific programme, department or faculty. The suggested simple 3-step approach used here to structure this article can provide a useful guide to organise thinking and put a block module plan together for action and implementation. Designing in evaluation points throughout is advisable so that changes can be made in response to feedback from students and own reflections and observation.

Regardless of the exact design, pattern, chunk, threshold concepts or even institutional constrains, effective, meaningful and timely communication amongst the members of the programme/teaching teams and with students is key. Communication needs to be clear, frequent and in various channels. Supporting students' learning is what matters and its effective communication has the potential to make a difference in student satisfaction and experience. If the COVID-19 pandemic has taught us anything it is that communities need to work closely together. Hence, as members of communities of learning, academics need to reach out to colleagues and students, share and test ideas. It is important to check with students what works for them and consider this information to design our offers so that they work for all.

International Journal of Management and Applied Research, 2020, Vol. 7, No. 4 


\section{References}

1. Bergmann, J. and Sams, A. (2012), Flip Your Classroom: Talk To Every Student In Every Class Every Day, USA: International Society for Technology in Education.

2. Biggs, J. (1996), "Enhancing Teaching through Constructive Alignment", Higher Education, Vol. 32, No. 3, pp. 347-364. https://doi.org/10.1007/BF00138871

3. Bloom, B. S. (ed.) (1956), Taxonomy of educational objectives: The classification of educational goals - Handbook 1, Cognitive Domain. New York: Longmans, Green, and Company.

4. Buckley, C., Nerantzi, C. and Spiers, A. (2017) Chapter 7 Enhancing learning and teaching with technology, in: Scales, P. (2017) An introduction to learning and teaching in higher education: supporting fellowship, Milton Keynes: Open University Press, pp. 107-116.

5. Chatzidamianos, G. and Nerantzi, C. (2020), "Stripping the layers of the onion" in learning and teaching in HE: positive lessons learned from working during a pandemic", AdvanceHE, [Online] Available from: https://www.advancehe.ac.uk/news-and-views/stripping-layers-onion-learning-and-teaching-he [Accessed on 3 October 2020].

6. Conole, G. (2013), Designing for learning in an open world. New York: SpringerVerlag New York. https://doi.org/10.1007/978-1-4419-8517-0

7. Davies, W. M. (2006), "Intensive teaching formats: A review", Issues in Educational Research, Vol. 16, No. 1, pp. 1-20.

8. Dixon, L. and O'Gorman, V. (2020), "Block teaching - exploring lecturers' perceptions of intensive modes of delivery in the context of undergraduate education", Journal of Further and Higher Education, Vol. 44, No. 5, pp. 583-595. https://doi.org/10.1080/0309877X.2018.1564024

9. Fenesi, B.; Lucibello, K.; Kim, J. A. and Heisz, J. J. (2018), "Sweat So You Don't Forget: Exercise Breaks During a University Lecture Increase On-Task Attention and Learning", Journal of Applied Research in Memory and Cognition, Vol. 7, No. 2, pp. 261-269. https://doi.org/10.1016/j.jarmac.2018.01.012

10. Garrison, D.R., Anderson, T. and Archer, W. (1999), "Critical inquiry in a textbased environment: Computer conferencing in higher education", The internet and higher education, Vol. 2, No. 2-3, pp. 87-105. https://doi.org/10.1016/S10967516(00)00016-6

11. Gilpin, S. (2020), "A Framework for Fostering Emerging Online Learner Persistence: The Role of Asynchronous and Synchronous Discussions", Journal of Teaching and Learning, Vol. 14, No. 1, pp. 29-42. https://doi.org/10.22329/jtl.v14i1.6253

12. Glazer, P. L. (2020), "The case for block scheduling in the fall", Inside Higher Ed, [Online] Available from: https://www.insidehighered.com/views/2020/05/06/advantages-block-schedulingcan-offer-when-colleges-reopen-opinion [Accessed on 18 October 2020].

International Journal of Management and Applied Research, 2020, Vol. 7, No. 4 
13. Grant, D. B. (2001), "Using block courses for teaching logistics", International Journal of Physical Distribution \& Logistics Management, Vol. 31. No 7/8, pp. 574-585. https://doi.org/10.1108/09600030110402987

14. Hackmann, D. G. and Schmitt, D. M. (1997), "Strategies for teaching in a blockof-time schedule", NASSP Bulletin, Vol. 81, No. 588, pp. 1-9. https://doi.org/10.1177/019263659708158802

15. Harasim, L. (2017), Learning theory and online technologies. $2^{\text {nd }}$ ed., New York: Routledge. https://doi.org/10.4324/9781315716831

16. Illich, I. (1971), Deschooling society, New York: Penguin books.

17. Jones, C., Aoki, K., Rusman, E. \& Schlusmans, K. (2009), A comparison of three open universities and their acceptance of internet technologies. Proceedings of the 23rd ICDE world conference on open learning and distance education, June 7-10, 2009, Maastricht, Netherlands, pp.85-93.

18. Ke, F. and Xie, K. (2009), "Toward deep learning for adult students in online courses", The Internet and Higher Education, Vol.12, No. 3-4, pp. 136-145. https://doi.org/10.1016/j.iheduc.2009.08.001

19. Kofinas, A., Bentley, Y., Minett-Smith, C. and Cao, G. (2017), "Block Teaching as the Basis for an Innovative Redesign of the PG Suite of Programmes in University of Bedfordshire Business School”, presented at the 3rd International Conference on Higher Education Advances, 21-23 June 2017, Valencia: Polytechnic University of Valencia Congress. https://doi.org/10.4995/HEAd17.2017.5379

20. Lave, J. and Wenger, E. (1991), Situated learning: Legitimate peripheral participation. Cambridge: Cambridge University Press.

21. Mazur, E. (1997) Peer Instruction: A User's Manual. Upper Saddle River: Prentice Hall.

22. Meyer, J. H. F. and Land, R. (2006), Overcoming Barriers to Student Understanding: Threshold Concepts and Troublesome Knowledge, Oxon: Routledge.

23. Nerantzi, C. (2020), "The use of peer instruction and flipped learning to support flexible blended learning during and after the COVID-19 Pandemic", International Journal of Management and Applied Research, Vol. 7, No. 2, pp. 184-195. https://doi.org/10.18646/2056.72.20-013

24. Nerantzi, C. (2017), Towards a framework for cross-boundary collaborative open learning in cross-institutional academic development, $\mathrm{PhD}$ thesis, Edinburgh: Edinburgh Napier University.

25. Nerantzi, C. and Beckingham, S. (2015), "BYOD4L: Learning to use own smart devices for learning and teaching through the 5C framework", in: Middleton, A., (ed.), Smart learning: teaching and learning with smartphones and tablets in postcompulsory education. Sheffield: Sheffield Hallam University, pp. 108-127.

26. Office for National Statistics (2019), Exploring the UK's digital divide [Online] Available

from: https://www.ons.gov.uk/peoplepopulationandcommunity/householdcharacteristics/

International Journal of Management and Applied Research, 2020, Vol. 7, No. 4 
homeinternetandsocialmediausage/articles/exploringtheuksdigitaldivide/2019-03$\underline{04}$ [Accessed on 2 October 2020].

27. Redden, E. (2020), "Rethinking the academic calendar", Inside Higher Ed, [Online] Available from: https://www.insidehighered.com/news/2020/04/20/beloitredesigns-its-academic-calendar-give-itself-more-flexibility-if-covid-19 [Accessed on 2 October 2020].

28. Robbins, P., Gregory, G. H. and Herndon, L. E. (2000), Thinking Inside the Block Schedule: Strategies for teaching in extended periods of time. Thousand Oaks: Corwin Press Inc.

29. Robinson, L.; Schulz, J.; Blank, G.; Ragnedda, M.; Ono, H.; Hogan, B.; Mesch, G. S.; Cotten, S. R.; Kretchmer, S. B.; Hale, T. M.; Drabowicz, T.; Yan, P.; Wellman, B.; Harper, M.-G.; Quan-Haase, A.; Dunn, H. S.; Casilli, A. A.; Tubaro, P.; Carvath, R.; Chen, W.; Wiest, J. B.; Dodel, M.; Stern, M. J.; Ball, C.; Huang, K.T.; and Khilnani, A. (2020), "Digital inequalities 2.0: Legacy inequalities in the information age", First Monday, Vol. 25, No. 7, https://doi.org/10.5210/fm.v25i7.10842

30. Rettig, M. D. and Canady, R. L. (eds.) (2013), Teaching in the block: Strategies for engaging active learners. New York: Routledge.

31. Salmon, G. (2000), E-moderating. The key to teaching and learning online. London: Kogan page.

32. Salmon, G. (2013). E-tivities. The key to active online learning, 2nd ed. Oxon: Routledge.

33. Sklar, J. (2020), "Zoom fatique' is taxing the brain: Here's why that happens", National Geographic Science, 27 April 2020, available from: https://www.nationalgeographic.co.uk/science-and-technology/2020/04/zoomfatigue-is-taxing-the-brain-heres-why-that-happen [Accessed on 3 November 2020].

34. Smyth, K. (2009), "Transformative online education for educators: Cascading progressive practice in teaching, learning and technology", in: Remenyi, D. (ed.), Proceedings from the 8th European conference on elearning, University of Bari, Italy, 29th-30th October. Sonning Common: Academic Conferences International, pp. 549-557.

35. Swann, W. (2004), Supported open learning: Reflections on a dynamic system. Milton Keynes: The Open University.

36. Swain, M. (2016), "Block teaching and the three A's: attendance, attainment and attitudes", Research in Practice, Vol. 10, No. 1, pp. 33-38.

International Journal of Management and Applied Research, 2020, Vol. 7, No. 4 